\title{
Sustainable fishing of inland waters
}

\author{
Jeppe KOLDING,,$^{*}$ Paul A.M. van ZWIETEN ${ }^{2}$ \\ ${ }^{1}$ Department of Biology, University of Bergen, High Technology Center, PO Box 7800, N-5020 Bergen, Norway; ${ }^{2}$ Aquaculture and \\ Fisheries Group, Wageningen University, PO Box 338, 6700 AH Wageningen, The Netherlands \\ *Corresponding author: jeppe.kolding@bio.uib.no
}

\begin{abstract}
Sustainability in fisheries has over the past decades evolved from a single species maximization concept to covering ecosystem and biodiversity considerations. This expansion of the notion, together with increased evidence that the targeted removal of selected components of the fish community may have adverse ecological consequences, poses a serious dilemma to the conventional fisheries management approach of protecting juveniles and targeting adults. Recently, the idea of balanced harvest, i.e., harvesting all components in the ecosystem in proportion to their productivity, has been promoted as a unifying solution in accordance with the ecosystem approach to fisheries, but this will require a fundamental change to management. In this paper, we review the objectives, theoretical background, and practicalities of securing high yielding fisheries in inland waters, with empirical examples from tropical freshwater fisheries which satisfy the extended objectives of minimal impact on community and ecosystem structure. We propose a framework of ecological indicators to assess these objectives.
\end{abstract}

Key words: balanced harvesting, freshwater fisheries, African lakes.

Received: June 2013. Accepted: October 2013.

\section{INTRODUCTION}

\section{Sustainability objectives}

The basic biological objective of fisheries management is to control the amount of fish that can be caught sustainably from a renewable resource - a stock or a fish community. In this context, sustainable means that a fishery can be carried out indefinitely without hampering the (re)productive capacity of the resource. Implicitly this also means that the productive basis of the resource, the ecosystem on which it depends, should also remain intact. Sustainability in fisheries is usually combined with a measure of optimisation, such as maximizing the sustainable catch (e.g. MSY), the economic revenue (e.g., MEY) or recreational value (e.g., amount of prize sized fish), as well as a minimization of the associated risk we accept that this becomes unsustainable, for instance the risk of stock collapse, decreased production or decreased availability of large sized fish. Maintaining stocks at a level that produce MSY is an old established fishery objective in international conventions. More recently, however, the ambient environment, in the form of the so-called Ecosystem Approach to Fisheries (EAF; Garcia et al., 2003), has gained focus in the sustainability debate and is increasingly adopted in policies. A key feature of the ecosystem approach includes conservation of the ecosystem structure and functioning. Thus the old objective of optimising certain outputs must now be combined with minimizing the impact on the ecosystem.

A definition of sustainability inherently includes what we want to extract: in fisheries the desired selection of species, amounts and sizes from a fish community. How much can be removed, the yield, is then dependent on the regenerative capacity of that selection set against a reference level that contains a particular sustainability criterion. How this selection is harvested depends on the interaction of the fished community with the fishing pattern applied, i.e., the combination of fishing gears and their probabilities of capture (see below). The Ecosystem Approach to Fisheries adds another dimension to sustainability as it recognises that a specific population is part of a tropho-dynamic system, where top-down (predation, competition) and bottom-up (food, production) processes shape its abundance and demographic structure. The added sustainability criterion is that the harvested selection should be taken in such a way that the productive basis, the habitats and food on which the resource depends, are least disrupted in order to maintain system resilience. Combined with the objective of conserving biodiversity this means that the natural demography and community structure resulting from production and predation processes should remain intact.

As the amount of catch (C), or yield, is a function of the available biomass $(\mathrm{B})$ of the resource and the fishing pressure $(\mathrm{C}=\mathrm{FxB})$, there are only two direct controls available to regulate fisheries: the amount of catch (output control), e.g. through Total Allowable Catch (TAC) or bag limits, and/or the pressure (fishing mortality) applied (input control). Fishing mortality $(\mathrm{F})$ in turn is a function of the total units of effort, a numerical component, and 
the efficiency of each unit. The efficiency is the average mortality rate that each unit imparts on the stock, also called catchability (q), or likelihood that targeted components are caught. A range of indirect controls to manipulate the production (stock and habitat enhancements) are available as well, and are sometimes used in inland water bodies (Kolding and Zwieten, 2006).

Barring methods that involve explosions, poisoning, obstructing or removing water that affect the whole ecosystem, all fishing methods are selective with regard to sizes, species and habitats fished. As aquatic communities are highly size structured (Kerr and Dickie, 2001), the particular efficiencies of different gears will affect the fish stock or fish community differently. From an ecosystem point of view the combined probability of capture on all species and sizes resulting from the overall combination of fishing methods applied, is important. This probability is called the fishing pattern. The overall fishing mortality on a fish community is thus the fishing pattern (how) times the number of units or fishing power (how much). Thus, the question of sustainable exploitation from an ecosystem point of view still has two main dimensions: how much to catch, and how to catch it, but this time it must satisfy both the demand of optimising yield of desired species and sizes and the demand of least disruption to demography and structure of the community. Fisheries science has conventionally focussed mainly on the how much question from a single species perspective and the how, or selectivity question became incidental to that. It has been directed by two mainly size selective principles in order to optimise production: the growth theory (let them grow) and the propagation theory (let them spawn at least once) (Froese, 2004), which both have a long history (Kolding and Zwieten, 2011). Selectivity, or lack of it, has also been an important element in the bycatch discussion, where the discarding of unwanted catch, which is mainly important in commercial fisheries, is being considered by society not only as wasteful but as unethical (Garcia et al., 2003). Thus, protecting juveniles, and avoiding bycatch has been a cornerstone in conventional fisheries management, to the point where unselective (indiscriminate) harvesting methods almost by default have been considered unsustainable (Kolding and Zwieten, 2011). However, over the past two decades a range of potential problems have gradually emerged that all appear to emanate from our selective harvesting of fish communities. Firstly, selective fishing on large adults does not always increase yields. On the contrary, from a community perspective size-at-entry fishing lowers potential yields (Conover and Munch, 2002; Garcia et al., 2012; Law et al., 2012, 2013) and secondly it has unintended ecological side effects. Targeted removal of large adult fish will result in earlier maturation and decreased adult body size (Law, 2000; Conover and Munch, 2002; Jør- gensen et al., 2007; Sharpe and Hendry, 2009; Van Wijk et al., 2013), with unknown evolutionary consequences. Demographic size truncation can result in increased population fluctuations (Anderson et al., 2008; Hsieh et al., 2010) and decreased population fecundity and resilience towards collapse (Pikitch et al., 2012). At the community level, selective fishing disturbs the trophic and demographic structure with cascading effects on the ecosystem (Rice and Gislason, 1996; Blanchard et al., 2005; Bundy et al., 2005; Daan et al., 2005; Guénette and Gascuel, 2012). Lastly the strong focus on selectivity has led to a range of regulatory induced bycatch and discarding issues (Kelleher, 2005; Diamond and Beukers-Stewart, 2011). Selectivity regulations are also creating governance problems. For small-scale freshwater fisheries in tropical regions the ubiquitous size- and gear limitations lead to never ending fights between managers and fishers over issues of catching undersized, immature and illegal fish (Misund et al., 2002; Kolding and Zwieten, 2011). The new ecosystem approach to management, with its demand to keep the ecosystem structure intact places selectivity issues, how to fish, at the centre of our concerns again.

\section{Stability and resilience}

Freshwater fisheries that mostly operate in fluctuating, climate driven environments point to another issue that is not well captured in classic single-species, steady state thinking about sustainability. These fisheries are adapted to continuous, seasonal and longer term, changes in fish communities as a result of fluctuating environmental forcing, and in regions where yield (food) is more important than commercial or recreational value they have a tendency to focus on the more productive parts of a fish community. Freshwater ecosystems are among the most diverse ecosystems in the world ranging from huge to diminutive and from relatively stable to highly unstable (sometimes ephemeral). The relative importance of top down (predation, fishing) versus bottom-up (nutrients, production) drivers will in general depend on the stability of an ecosystem and the resilience of its components (Kolding and Zwieten, 2006). Thus, the capacity of a fish community to persist under stressors such as fishing, predation or environmental forcing is theoretically associated with these two concepts. Because of their time-dependency any measure of stability and resilience should be viewed in relation to the life span and the speed of regeneration of species and sizes in a fish community: the mortality rate or the biological turnover rate (intrinsic growth rate $\mathrm{r}$, or $\mathrm{P} / \mathrm{B}$ ratio). What determines stability and resilience therefore depends on the configuration and combination of the ambient stress pattern (continuous selective or discrete non-selective mortality), and the trade-off between the advantages of being big and competitive and the probability of dying before reaching reproductive age (i.e., the trade-off between growth and 
reproduction). Kolding and van Zwieten (2006) condensed these ecological concepts and processes into two main categories where the relative stability of the environment determines the prevailing mortality pattern and hence shape the resilience of its inhabitants to such stressors:

i) Unstable environments with discrete, density independent, non-predictive, non-selective mortality induced by physical changes and abiotic drivers.

ii) Stable environments with continuous, density-dependent, predictive, and size-selective mortality (mainly on juveniles) induced by the biotic community as predation.

While the two categories represent extremes on a gradient, (in)stability must be seen in relation to the mean generation time of populations. Thus, even for the unstable environment there are two basic life-history strategies; either follow the fluctuations (boom- and -bust ephemeral species), or endure the disturbances (long-lived resistant species). For the latter, the environment may no longer be unstable, only periodic (Winemiller and Rose, 1992; Kolding, 1994). A range of climatic, morphologic and edaphic factors correlate with freshwater productivity, but the hydrodynamic regime - particularly in tropical systems - play a significant role in the injection and re-suspension of nutrients, and thus has a strong influence on the dynamics of biological communities and productivity (Ryder et al. , 1974; Kolding and Zwieten, 2006). Thus, by examining different time scales of water level fluctuations, freshwater environments can be ordered in terms of system stability (Jul-Larsen et al. , 2003).

To capture these processes, Kolding and Zwieten (2012) proposed to use a Relative lake Level Fluctuation (RLLF) index, defined as lake level oscillations over seasonal or inter-annual time scaled by the mean depth of the system, as an indicator and a proxy for environmental stability and bottom up productivity. In terms of sustainability, RLLF showed a clear positive relationship with productivity, and system resilience, and a negative relationship with system size and diversity. This physical (hydrological) based continuum has strong associations with the biologically based $r$-K continuum (Pianka, 1970), but this time with an explicit explanatory variable, the prevailing sizeselective mortality pattern (Kolding, 1993): from non-selective and density independent ( $r$-selection), to juvenile size-selective and density dependent (K-selection). Fishing is also selective mortality and the pattern is mostly opposite to K-selection. In fact the various symptoms of adult sizeselection described earlier all indicate that fisheries tend to induce $r$-selection on the communities they exploit.

\section{The optimal exploitation pattern}

So, what is an optimal and sustainable fishing pattern from a dynamic freshwater ecosystem perspective? From the arguments above it follows that different communities have adapted to different environments, each with their own specific mortality (survival) pattern, and that size-selective mortality (where size is a function of stability as it takes time to grow) plays a big role in this adjustment (Kolding, 1993). Selective removal by fishing must therefore also have an effect in the long run, as we now see emergent signs of. Conversely, a fishing mortality that closely emulates the natural mortality pattern should theoretically induce the least demographic changes. So the question is: can we create a fishing pattern where natural mortality is simply replaced by fishing mortality to produce high sustainable yields? In the remainder of this paper we will show that a fishing pattern that distributes a moderate mortality across the widest possible range of species and sizes in an ecosystem in proportion to their biological production, so-called balanced harvesting (Garcia et al., 2012), will satisfy both fishery objectives and conservation objectives. Such a fishing pattern can only be obtained by fishing with a varied balanced multitude of different fishing methods, adaptable to the specific hydrodynamic regime of an ecosystem. Many freshwater fisheries, in particular in the developed world are gradually transforming into recreational fisheries, but where the two fisheries still co-exists there are often mutual conflicts based on different objectives (high yield versus trophy specimens). An additional bonus of balanced harvest is that a sports fishery on prize sized specimen of fish are completely reconcilable with commercial harvests if the former are organised as catch and release fisheries and the latter have maximum size limits instead of minimum (Gwinn et al., 2013). Supported by recent theoretical developments, we will illustrate these principles with empirical examples from African freshwater fisheries, which appear to have evolved closely towards balanced harvesting. From this we will propose a framework of indicators to analyse sustainable, high yielding fishing patterns in fluctuating environments.

\section{Balanced harvesting: theory and application}

Recent work on a range of multispecies fisheries, ecosystem and size-spectrum models suggest that fishing patterns operating with a moderate mortality in proportion to biological production, and spread across a wide range of sizes on all fish in a community, maximise yield while conserving biodiversity and size structure better than conventional selective removal based on single species optimisation of yield (Bundy et al., 2005; Zhou et al., 2010; Garcia et al., 2012; Law et al., 2012, 2013). Size-spectrum models in particular give rise to a different view on ecosystem and community perturbations due to fishing. Results from these models will be used here to derive a framework of analysis of the sustainability of fished communities in freshwaters. As the results from these models are so diverging from traditional single species fisheries models, as for 
instance the widely applied yield-per-recruit (YpR) models (Beverton and Holt, 1957), a short description is required. Size-spectrum models have their root in the observation that total biomass per unit volume in aquatic ecosystems in logarithmically-scaled bins of body mass is roughly equal (Sheldon et al., 1972; Kerr and Dickie, 2001), which results in a strongly size structured biomass distribution with a uniform slope across the log-transformed biomass-size spectrum. This typical demographic structure of aquatic communities, comes about as virtually all organisms start ontogeny as tiny larvae, act in their early life as prey for larger predators and grow through a range of trophic levels during their development until adulthood (Jennings et al., 2001). Unlike terrestrial ecosystems, there are usually neither large herbivores nor large plants in open aquatic environments as most primary production must start in the narrow euphotic surface layer with no foothold and strong turbulence, which require miniscule body sizes to persist. The aquatic food chain must therefore, in general, begin at the microscopic phytoplankton level and most organisms must run the gauntlet of predation while growing to adult size. This, perhaps, can explain the very high fecundity of many aquatic organisms compared to terrestrial equivalents. However, the steady loss of mass due to assimilation efficiencies of around $20-25 \%$, will - on a logarithmic scale
- result in the typical triangular shaped biomass-size distribution (Fig. 1).

Size-spectrum models keep track of biomass changes in an ecosystem by explicitly linking growth and mortality through predation. Thus fish grow dependent on how much they eat, while most fish die because they are eaten. The flow of biomass from small to large organisms is internally accounted for through the feedbacks between growth and available food, between assimilated food and reproduction, and between mortality and predation. The typical triangular biomass-size structure of aquatic communities emerges from these feedback and dissipation processes, while changes in diet and mortality captured through this internal accounting result in changes in the size structure. This is a fundamentally different approach than single species YpR models where two independent external growth and decay functions (usually according to a von Bertalanffy growth equation and a negative exponential mortality function) determine the rates of change in biomass. In these models there is no accounting for food, which is assumed present and for free. As a result of this free lunch assumption, the general recommendation from YpR models to optimise yield is to delay fishing mortality (by regulating size-at-entry) until the balance between mortality and growth has peaked. How-

\section{abundance}

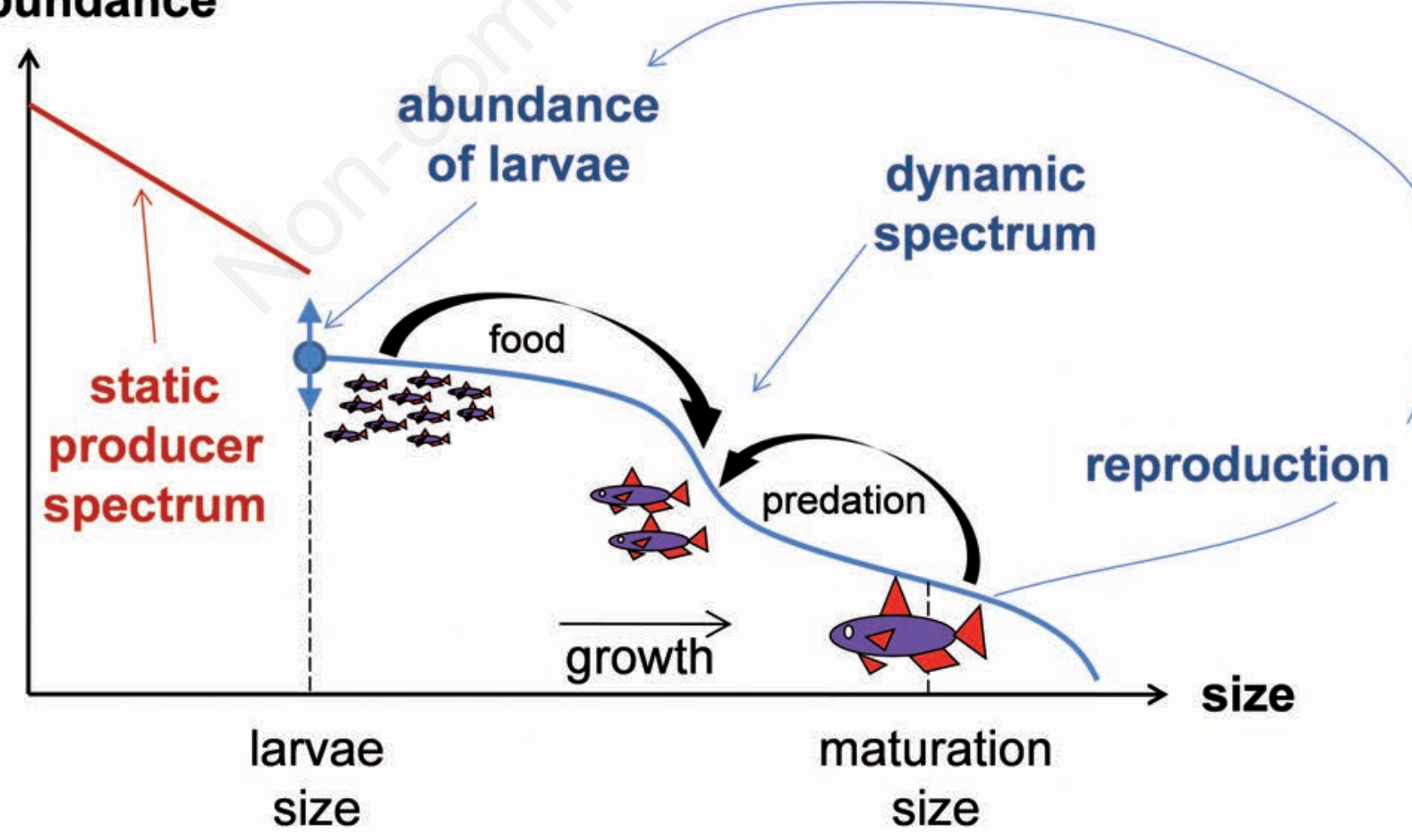

Fig. 1. A dynamic size spectrum model for abundance as a function of body size, over the course of time $t$ in a fish community feeding on itself and on plankton delivered by a static producer spectrum. 
ever, when accounting for food and assimilation loss (it takes approximately $4-5 \mathrm{~kg}$ of prey to produce $1 \mathrm{~kg}$ predator), the size-based models shifts the whole focus to the more productive areas of the ecosystem, which are generated at lower trophic levels and smaller/younger individuals in a population or community (Fig. 1). Then a delayed size-at entry fishing does not produce the highest sustainable yields in contrast to fishing patterns targeting juveniles and protecting large mature adults, where a truly balanced harvesting pattern produces the highest sustainable yields (Law et al., 2012). Apart from the criterion of sustainable yield Law et al. (2012) evaluated the impact of different fishing patterns on two additional criteria: i) the resilience of a system to disturbances and ii) the disruption of the natural size structure of system caused by exploitation. Again resilience and disruption deviated most at conventional size-at-entry fishing with minimum size limits, while the greatest resilience to disturbances and least disruption of the size structure were obtained by a balanced harvesting pattern. A size based framework of analysing fisheries derived from similar physiologically structured, size-spectrum models is also proposed by others (Andersen and Beyer, 2006; Andersen et al., 2009). We will now describe some empirical examples of freshwater fisheries that seem to be close to balanced harvesting principles.

\section{EMPIRICAL CASE STUDIES OF BALANCED HARVEST}

All fishing gears are size and species selective and are deployed in particular habitats or seasons. A harvest that is targeting all components over a large size-range can therefore only be achieved by a range of different gears that are flexibly used in time and space over available habitats. While very few fish communities are fished unselectively or in balance with their biological production the actual impact of non-selective illegal gear has been studied in some small scale inland fisheries in Africa (JulLarsen et al., 2003), which in practice are largely unregulated due to lack of enforcement. In most African artisanal fisheries, small fish is often preferred due to availability, ease of preservation, transport, preparation and taste. In these fisheries fishing patterns appear to converge towards the available biomass in the fish community rather than selecting for species or size. Fisheries in Lake Volta, Ghana, highlight the flexible effort dynamics required to potentially achieve such fishing patterns (Zwieten et al., 2011). The traditional Bangweulu swamps fishery in Northern Zambia has customized a fishing pattern that largely reflects the regenerative processes of the fish community and therefore appears to be in ecological balance (Kolding et al., 2003b). Lastly we will use the ex-

\begin{tabular}{|l|l|l|l|l|}
\hline Gear & Jan Feb Mar Apr May Jun & Jul Aug Sep Oct Nov & Dec \\
\hline Palm trap & Receding water level & Rising water level & \\
\cline { 2 - 5 } Hook (Bagrus) & & & & \\
Nifa-nifa & & & & \\
Beach seine & & & & \\
Acadja & & & & \\
Ripping hook & & & & \\
Gillnet & & & & \\
Bamboo pipe & & & & \\
Winch net & & & & \\
Wangara & & & & \\
Drift net & & & & \\
Cast net & & & & \\
Tilapia trap & & & & \\
Hook (Lates) & & & & \\
Lift basket & & & & \\
\hline
\end{tabular}

Fig. 2. Seasonality in gear use on Lake Volta. Gears: light grey, used; black, best period; white, not used. Periods of receding (white) and rising (dark grey) water levels are indicated. After Zwieten et al. (2011). 
amples of Lake Kariba and Lake Mweru to show how yields increase when shifting to the small sized part of the community and in doing so will bring the harvested community to a similar structure as a non-harvested situation (Kolding et al., 2003a; Zwieten et al., 2003).

\section{Volta}

Lake Volta in Ghana is a huge reservoir of around 8500 $\mathrm{km}^{2}$ created in 1964. While effort and landings statistics are sketchy, the lake supports around 100,000 fishers producing up to 250,000 tonnes per year (Zwieten et al., 2011). Around 74 out of 121 recorded species are important in the fishery (Dankwa et al., 1999). The abundance and composition of the fish community is dependent on the seasonal and inter-annual water inflow. Each year between 155 and $1800 \mathrm{~km}^{2}$ of land is temporarily inundated by rising waters, creating vast new habitats for fish. As the inflowing waters are relatively low in nutrients, the seasonal flooding of large tracts of land, that are grazed or cultivated during the dry season, most likely explains the high and variable annual productivity of the reservoir (Zwieten et al., 2011). Fishers around Lake Volta have, over the past 50 years, developed a highly diverse array of at least twenty-seven different types of fishing gear to harvest this production (for a full description see van Zwieten et al., 2011). The median daily catch rate of all gears was $25 \mathrm{~kg}^{\text {.boat }}{ }^{-1}$, but varied between

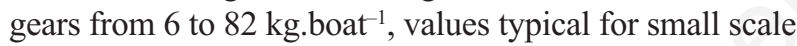
freshwater fisheries with limited technological development. The annual catch of a canoe is on average about 7.5 tonnes year $^{-1}$. With two or three fishers per boat this gives an average catch of 2.5-3.8 tonnes fisher ${ }^{-1}$. year $^{-1}$, which is in the same range of remarkably consistent values among other African freshwater fisheries (Jul-Larsen et al., 2003; Kolding and Zwieten, 2006; Zwieten et al., 2011).

Gear regulations are heavily influenced by the former colonial administration and motivated by conventional fisheries theory, but not well enforced and include: i) a minimum legal mesh size in traps and nets of $50 \mathrm{~mm}$ stretched for multifilament and $75 \mathrm{~mm}$ for monofilament; ii) banning of any active towed or moving gear like seine nets, lift nets and trawls, as well as drive fishing; and iii) a number of specific gears that are deemed too efficient or target egg bearing life-stages of fish. Thus, the majority of fishing gears in Lake Volta are technically illegal but regulations are ignored by fishers.

Most gears are used seasonally over different periods of the flood cycle (Fig. 2), as well as in different habitats. All of them catch a range from at least 9 up to 56 species. lake level fluctuations affect the spatial and temporal allocation of effort, and fishers frequently shift between gears and different habitats in the course of a year. As the surface area of the reservoir decreases during drawdowns, the fish migrate to deeper waters, creating concentrations of fish assemblages requiring specific pelagic and demersal fishing methods. Rising water levels provide opportunities for floodplain fish species to spawn in the submerged vegetation, as well as food and shelter for those species that prefer shallow water, requiring other, shallow water, fishing methods. Each gear appears to have a distinct trophic signature (TS) that ranges between 2 and 4.5 (Fig. 3). Furthermore each gear targets a specific length range: most fish caught are between 4 and $35 \mathrm{~cm}$. Fishers with different fishing gears are behaving like niche separating predators, each with their own speciality to capture preferential prey. The result of such niche portioning, resulting from strong competition and vast and variable seasonal changes in fishable habitat, could be an overall ideal free distribution of fishing pressure on virtually all available resources over different seasons.

\section{Bangweulu}

Fishing in the vast oligotrophic Bangweulu floodplain and swamps in Northern Zambia is the single most important economic activity in the area, and the fishery is the second most important in the country. The ecosystem and the fishery are highly dependent on the seasonal and inter-annual wax and wane of the water levels, causing large areas of floodplains to be temporarily inundated. The amount of rain is the main environmental driver, and good fishing years are preceded by years of high precipitation. In this unstable habitat, most fish species are small, hardy, fast growing and with a high biological turnover. A stock assessment performed 15 years ago found no indications of biological overfishing (Kolding et al., 2003b). The local fishing methods, which have not changed much in the recorded history (Brelsford, 1946), are adapted to catch a high variety of predominantly small fish in a range of shifting habitats. The fishery consists of a seasonally changing mixture of weirs, long-lines, seines, and gill nets (Huchzermeyer, 2013) - the latter often combined with drive fishing ${ }^{1}$-, all adjusted to the annual flood cycles. The main fishing season (May to November) is during water recession after the peak flood, when all fish and juveniles breeding/feeding on the floodplains are forced back into the permanent water bodies, consisting of isolated pools, main channels and swamps. Competing for space, the fish community enters a period of high mortalities from avian predation, reduced water quality, and stranding. The earth dams (weirs) on the grassy floodplains only operate for a few weeks of April and May, but in that period yield high catches while the receding water carries mostly juvenile fish to the swamps. The reed weirs

\footnotetext{
1 Driving fish into a gillnet by beating the water with clubs or paddles (so-called kusikila or kutumpula).
} 
in the permanent swamp channels come into operation around June-July and only last to August-September. From August to November the drive fishery for breams and the longline fishery for the larger predators (catfish and tigerfish) start in the lagoons and open channels.

The fisheries regulations in Zambia, like in Ghana, are inherited from colonial times and have roots in classical fisheries theory and terrestrial game legislation (Malasha, 2003). In Bangweulu they consist of i) a closed fishing season from the first of December to the first of March (coinciding with the period of rising water and low fish concentrations); ii) a minimum mesh size limit of $51 \mathrm{~mm}$ (2") stretched mesh; iii) all forms of active fishing, including drive fishing and seines, are prohibited. Although not explicitly mentioned in the fisheries act, weirs are generally regarded as illegal gears as well due to their fine meshed traps. In practice, however, regulations are ignored. Nearly $80 \%$ of the fishing gears and mesh sizes are technically illegal (Tab. 1). The strong divergence between the traditional and established fishing pattern versus the legal framework, has for decades caused serious
Tab. 1. Total number of fishing gears by type and mesh size for the Bangweulu swamps (frame surveys, 1992, 1996). Modified from Kolding et al. (2003b).

\begin{tabular}{lccccc}
\hline $\begin{array}{l}\text { Mesh size } \\
(\mathrm{mm})\end{array}$ & \multicolumn{4}{c}{ Total number of gear by type } & Mesh size \\
\hline 3 & Gillnets & Kusikila & Seines & Weir traps & (cum \%) \\
4 & & & & 3869 & 13 \\
6 & & & & 3358 & 41 \\
8 & & & & 2322 & 49 \\
25 & 534 & 17 & 53 & & 50 \\
38 & 6719 & 68 & 178 & & 52 \\
50 & 4233 & 135 & 49 & & 75 \\
63 & $\mathbf{1 2 6 0}$ & 643 & & & 90 \\
76 & $\mathbf{5 5 4}$ & 74 & & & 97 \\
89 & $\mathbf{1 3 6}$ & & & & 99 \\
127 & 255 & & & & 99 \\
\hline Total & 13,691 & 937 & 280 & 14,936 & 29,844 \\
$\%$ & 46 & 3 & 1 & 50 & 100 \\
$\%$ legal & 22 & & & & \\
\hline
\end{tabular}

Legal gears are in bold and italics; all other gears are illegal; weirs are considered illegal because of the small mesh sizes in their traps.

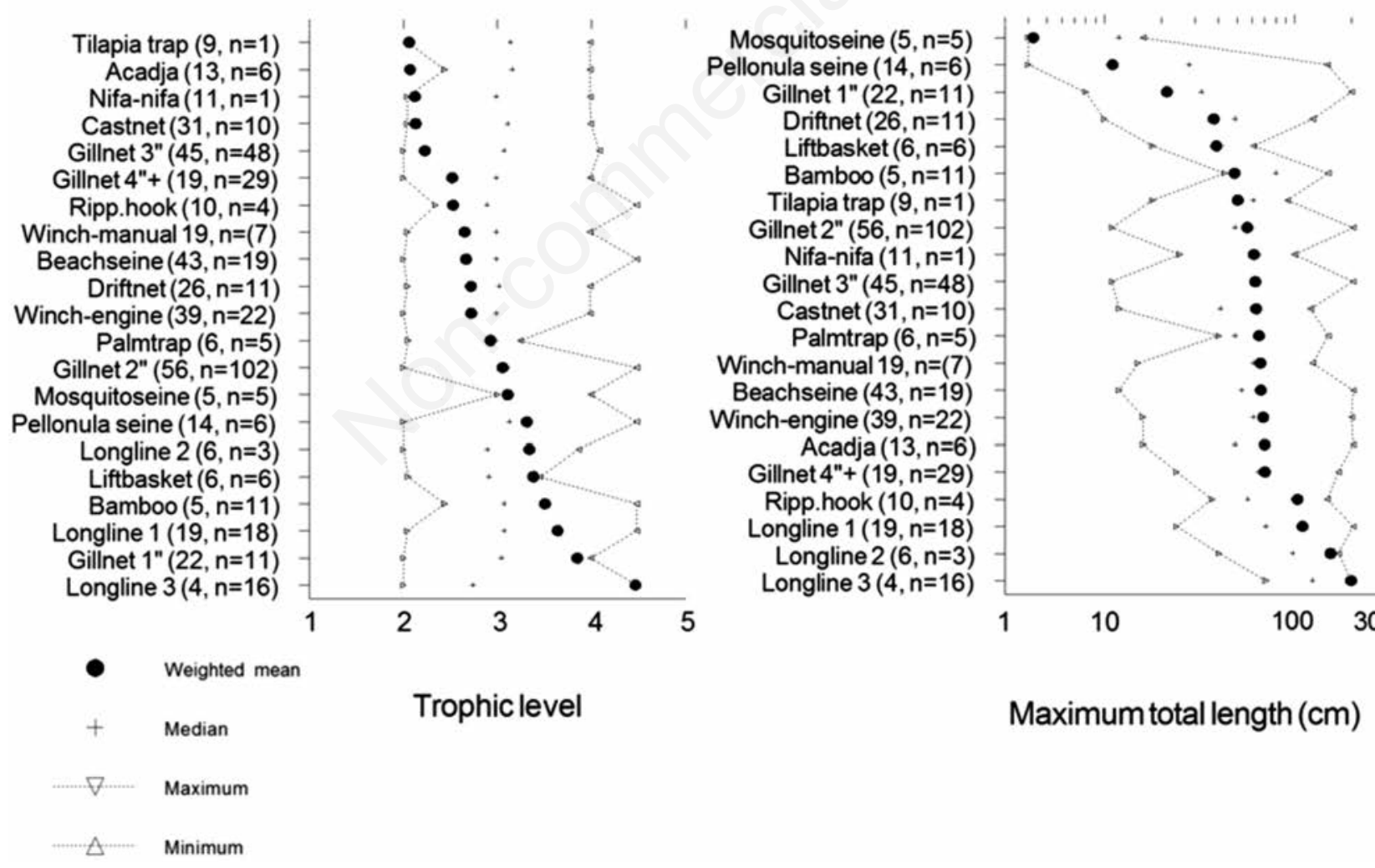

Fig. 3. On the left panel, the mean trophic level of the catch of 21 fishing methods (out of 27), and the trophic signature of a gear, calculated by taking the (adult) trophic level from Fishbase (www.fishbase.org) of each species weighed by their proportional abundance in the catch. On the right panel, the average maximum size of individual species over all species caught in gears operated in Lake Volta, Ghana. In brackets the number of species caught by a gear, followed by number of samples (n) over which the proportion is calculated. After Zwieten et al. (2011). 
conflicts between fishers and managers resulting in a breakdown of confidence and trust between the parties (Chanda, 1998). Local administration and many NGOs generally claim that the fish stocks are heavily fished, perhaps even threatened, by high fishing pressure. Recurrent fears have been expressed that the fishery of the Bangweulu system has undergone alarming changes indicated by the small sizes of fish caught and a general decline in individual catch rates. Fishermen are believed to cause these changes by an intensified utilisation of illegal gears.

A formal assessment of the fish stocks in the Bangweulu swamps to establish their level of exploitation (Kolding et al., 2003b) revealed that the seven most important species together accounted for $80 \%$ of the total catches (Tab. 2). The top most important species by volume is the small shoaling invertebrate feeding snoutfish (Marcusenius macrolepidotus). The catfish (Clarias gariepinus) is one of the larger predators in the system. The adults are mainly caught in gillnets and longlines, while the juveniles are caught in large quantities in the seasonal floodplain weirs. The remaining five are all cichlids: two are predators (Serranochromis angusticeps and $S$. robustus), one is the herbivore redbreast bream (Tilapia rendalli), and the last is the small ubiquitous omnivore banded tilapia (T. sparmanii). The fishing pressure on each population was measured in terms of the exploitation fraction (E): the total annual catch (C) divided by the annual production (P). There is usually a clear positive trend between the exploitation fraction and size. This is illustrated by correlating the size range of exploitation with the mean exploitation fraction (Fig. 4). Contrary to expectations, the results revealed that the only stocks that were technically overexploited $(\mathrm{E}>0.5)$, were the largest predators (Clarias gariepinus, Hydrocynus vittatus and Serranochromis robustus) caught in the legal gears (gillnets and hooks). Theoretically, a 50\% reduction in fishing effort on these species would increase production with approximately 30 tons per year, which is less than $0.5 \%$ of the total fishery. However, if enforcing the legal fishing pattern, total landings would be more than halved as the majority of the sustainably exploited stocks were caught by illegal methods (Tabs. 1 and 2). 90\% of the gillnet catches, mainly small species like $T$. sparmanni and $M$. macrolepidotus, were taken in mesh sizes smaller than the legal $50 \mathrm{~mm}$ stretched mesh and all were low to moderately exploited. Theoretically these species could be submitted to a higher fishing pressure to increase yields, but again the effect would be rather small. Only the smallest species in the system were under-utilized and could sustain a substantially higher fishing pressure. The overall conclusion from the stock assessment was that the yield obtained with the observed combination of gears (including illegal) and effort was remarkably close to the potential long term maximum sustainable yield summed for each species over the fish community (multispecies MSY).

When comparing the Bangweulu fishing pattern with the available biomass-size distributions of the fish stocks (Fig. 5), where most of the standing fish biomass is from specimen and species smaller than $15 \mathrm{~cm}$ in length (approximately $90 \%$ of the measured biomass was less than $25 \mathrm{~cm}$ ), it becomes clear that the traditional combination of fishing methods to a large extent is balanced with production. Ideally, the slope of the catch curve should be parallel with the slope of the biomass distribution for the fishery to be perfectly balanced, but as larger fish are relatively more exploited than small (Fig. 4), the slope of the catch curve is less than the slope of the standing biomass. These data clearly illustrate the ironic paradox of the ongoing tug-of-war between the traditional fishing pattern and the current management legislation, which, if enforced, would only result in more overfishing on the large fish and drastically reduced total yields. Not surprisingly local fishers in Bangweulu do not abide to the regulations.

\section{Mweru}

The fisheries of Lake Mweru-Luapula and its associated floodplains and swamps in Northern Zambia have

Tab. 2. The seven species in the Bangweulu fishery comprising $80 \%$ of the total catches, and their main method of capture (1994-1997 surveys). Data in Chanda (1998) and Kolding et al. (2003b).

\begin{tabular}{lccccc}
\hline Species & Main method & Total catch $(\mathrm{t})$ & Percent of total & P/B & Average exploitation \\
\hline Marcusenius macrolepidotus & Seines, weirs & 1570 & 18 & 3.7 & 0.38 \\
Tilapia rendalli & Kusikila & 1195 & 14 & 2.7 & 0.37 \\
Serranochromis angusticeps & Kusikila & 1101 & 13 & 1.8 & 0.35 \\
Clarias gariepinus & Weirs, gillnets & 1013 & 12 & 1.4 & 0.47 \\
Serranochromis mellandi & Weirs, gillnets & 874 & 10 & 2.1 & 0.41 \\
Serranochromis robustus & Kusikila & 739 & 8 & 1.8 & 0.54 \\
Tilapia sparrmanii & Gillnets & 487 & 7 & 3.0 & 0.04 \\
\hline Total & & 6979 & 80 & 2.4 & \\
\hline
\end{tabular}

The exploitation rates (= fraction of total production harvested) are weighted averages over all methods; an exploitation value higher than 0.5 is considered overexploited. $P / B$, annual production to biomass ratio. 
historically been important for food security in the wider region. Since the beginning of last century fishing is closely linked by trade to the towns of the Copperbelt and the diamond mines in Zambia and Congo (Gordon, 2000). The river and lake area became fully accessible around 1944, when the crocodile populations were decimated. An ancient and important fishery on the cyprinid Labeo altivelis rapidly collapsed in the 1940s when European fishers targeted the fish for its eggs during upriver spawning migrations (Gordon, 2006). Between 1965 and 1970, when large-meshed gillnets were still predominant, total catches of the indigenous cichlid Oreochromis mweruensis declined severely, which lead to concern about its sustainability. Two decades later, despite an enormous increase in fishing effort (Tab. 3), this species returned as one of the most important stocks in the fishery, and together with other cichlids, has remained dominant in the fishery and trade up till today. Fishing patterns changed and diversified over the recorded history: large traps and stationary cotton gillnets were replaced by multifilament nylon gillnets during the 1960s. Since then the dominant mesh sizes have gradually decreased from $102 \mathrm{~mm}$ to 63 $\mathrm{mm}$; active methods as drive-fishing and seining became prevalent, all of which are illegal. In the early 1970s a new dipnet fishery with light attraction on a small pelagic freshwater clupeid (chisense, Microthrissa moeruensis), - a species reaching a maximum size of $5 \mathrm{~cm}$ - started, which is now the most important fishery in terms of production (Tab. 3). A range of other fishing methods are used, and continue to diversify, for instance when in 1990s Fish Aggregating Devices (FADs) were introduced targeting the hitherto unexploited small specimens of the torpedo robber Alestes macrophthalmus (Kapasa, 1998).

The shift towards smaller mesh sizes and the diversification of fishing methods from the 1970s onwards have increased the total yields by a factor 5-6. The decrease in mesh sizes is a necessary response under increased effort to maintain individual catch rates, as it shifts the target towards the smaller elements of the fished community with the highest biomass and turnover rates. Though the relative abundance of large fish have generally decreased no species have disappeared from the system, and the overall decrease in mesh size was actually followed by a recovery (increase in average size and biomass) of the preferred O. mweruensis (Fig.

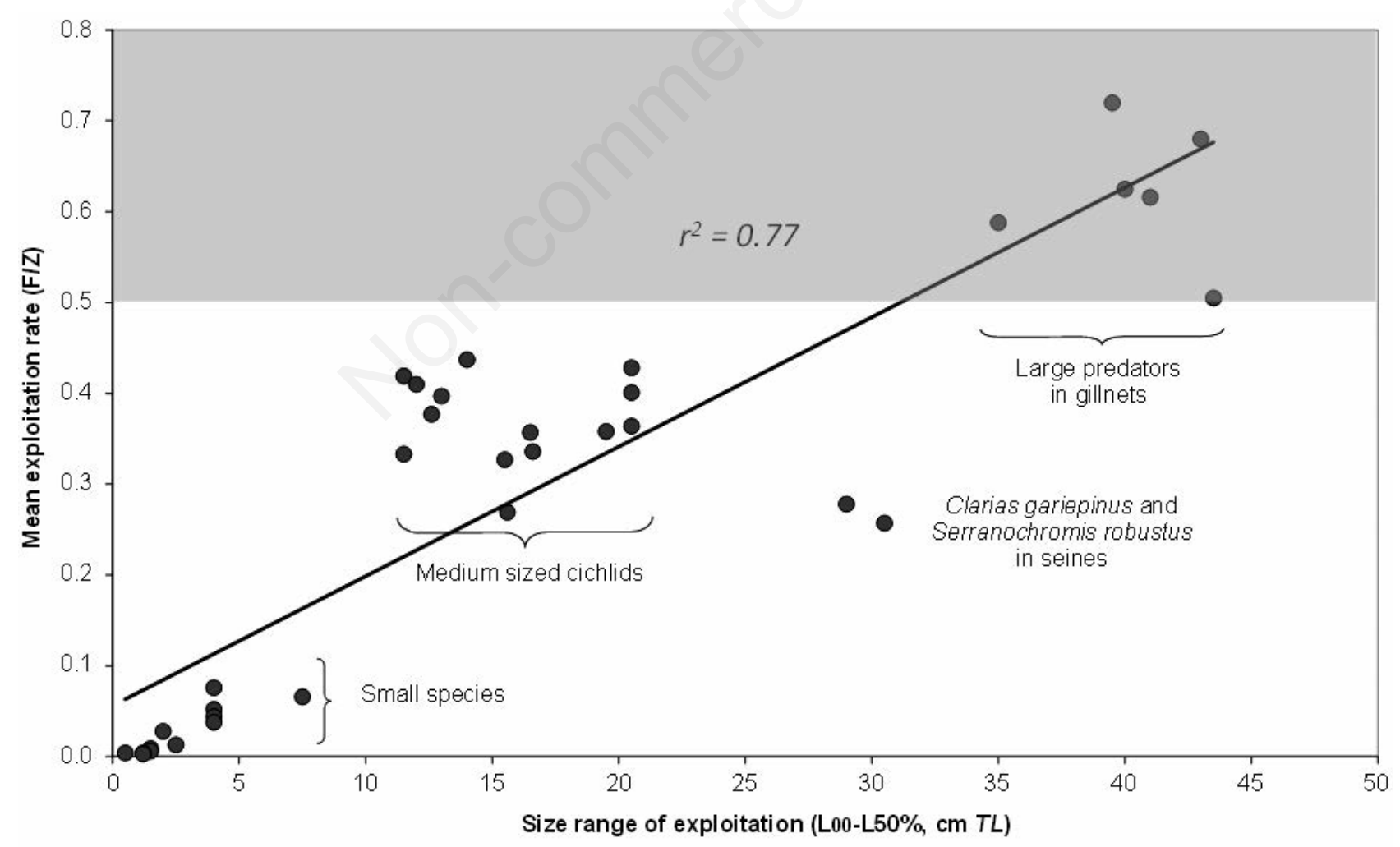

Fig. 4. Exploitation rates of all species investigated in all gears except weirs plotted against their average size range of exploitation. Exploitation rates $(\mathrm{F} / \mathrm{Z})$ are the fraction of the total production harvested. $\mathrm{F} / \mathrm{Z}<0.5$ (=max $50 \%$ of total production caught) is considered safe. Only the largest predators (C. gariepinus and H. vittatus) are technically overfished. For all the smallest species in the Bangweulu system the harvest rates are less than 10\%. From Kolding et al. (2003b). 
6). Between the 1970s and the 1980s the slope of the biomass size distribution remained the same while the intercept decreased significantly, indicating a decreased standing biomass. Since then the slope increased significantly, while the intercept restored to the 1970-ies level. This represents a clear shift to smaller sizes. Closer inspection of the sizestructure diagrams shows that since 1980s the biomass of maximum sizes $(79-82 \mathrm{~cm})$ in the community remained the same, but that of intermediate sizes around $30-40 \mathrm{~cm}$ increased (Fig. 6). No data are available on the size structure over the last decade up to 2008 when numbers of fishers doubled and numbers of nets even quadrupled. But as the relative distribution of mesh sizes has remained the same, while the overall yield in the gillnet and dipnet fishery in fact increased, it appears that the increased effort in the Lake Mweru fishery has been accommodated by increasingly targeting the highly productive but smallest sizes of the fished community components.

\section{Kariba}

Lake Kariba on the Zambezi River between Zambia and Zimbabwe is, like Lake Volta, a man-made reservoir created primarily for hydro-electricity. But the lake also supports an important fishery where the two sides of the lake, partly for historical reasons, have been managed under very different scenarios. While Zimbabwe has applied, and enforced, internationally accepted methods in the form of effort restrictions and mesh-size limitations, the fishery in Zambia has largely been open access with no enforced regulations (Kolding et al., 2003a). Unintentionally, therefore, the lake can serve as a grand-scale experiment comparing a managed fishery with an un-managed. Like elsewhere, fish production in Lake Kariba fluctuates in accordance with the hydrodynamic regime (Karenge and Kolding, 1995), but while the overall biomass levels are high and overall stable in in Zimbabwe, they are low and decreasing in Zambia (Kolding et al., 2003a). This is in accordance with expectations when comparing a regulated fishery versus an open access situation with high uncontrolled effort. Under decreasing individual catch rates, the only way for the fishers to remain in the fishery is to decrease the mesh-sizes and fish lower in the food-web. Like in Lake Mweru, this is also observed on the Zambian side of Lake Kariba, where the

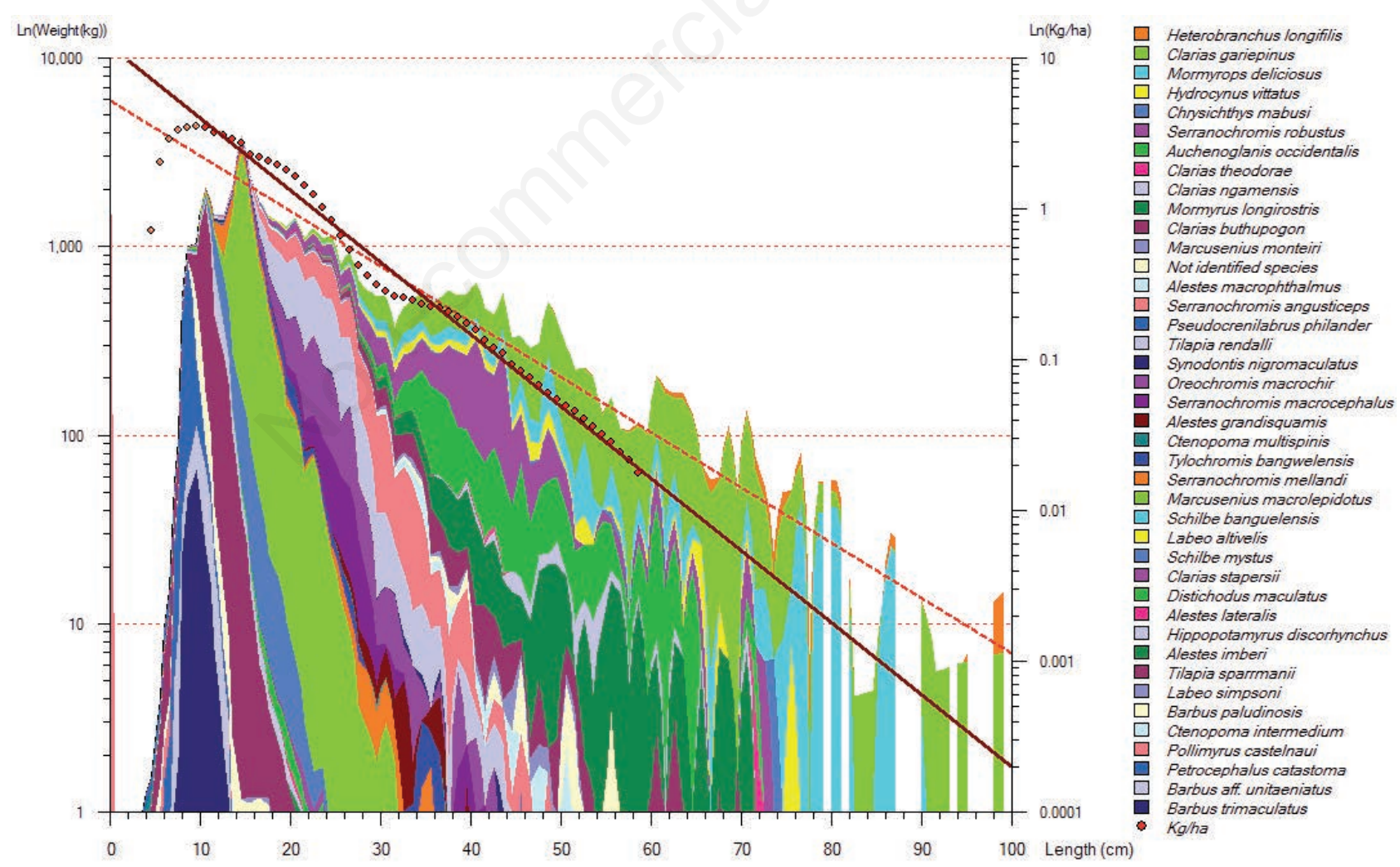

Fig. 5. In-transformed cumulated weight (left Y-axis, $\mathrm{kg}$ ) by species and body size $(\mathrm{cm})$ caught by all major fishing methods in Bangweulu (1994-97 surveys). Each colour represents a species. Superimposed (right Y-axis, diamonds, full line) is the total ln-transformed biomass-size distribution of the 13 most important species in $\mathrm{kg} \cdot \mathrm{ha}^{-1}$. The slope of the combined catches (broken line) is less steep than the community biomass (full line) in correspondence with larger species being more exploited. Adapted from Kolding et al. (2003b). 
average mesh size of the fishing fleet has decreased over the past 25 years resulting in a corresponding decrease in the mean size of the fish caught (Kolding et al., 2003a). Both these indicators, the decreasing catch per unit of effort (CPUE) and the decreasing mean size of the fish caught, have been interpreted as standard symptoms of overfishing. Surprisingly, however, the stocks in Zambia are not overfished (Kolding et al., 2003a), and the total yield is about 6 times higher than in Zimbabwe. Thus the gradual transformation of the fishing pattern in Zambia towards the smaller, but more productive, components of the ecosystem has tuned the fishery to be in balance with the ecosystem productivity. Comparing the heavily exploited Zambian fish community with an unexploited control community from an area permanently closed to fishing (Fig. 7), shows that the two communities are identical in structure and composition, and only differ in terms of standing biomass. In other words, the technically illegal and unregulated Zambian fishery has by self-regulation (effort and fishing pattern appears dictated by the productivity) achieved a sustainable ecosystem approach to fishing. These results illustrate that our conventional management tools, by prohibiting capture on small species and sizes, will neither maximize the yields, nor maintain the internal structure of the exploited ecosystem, thus resulting in failure to achieve the desired objective of an Ecosystem Approach to Fisheries.

\section{DISCUSSION}

The conventional management approach for achieving high yielding sustainable fisheries has been based on the let them spawn and let them grow paradigm (Froese, 2004; Kolding and Zwieten, 2011). Consequently, minimum size regulations and/or gear restrictions to control the selective targeting of specific parts of the fish community are found in virtual every fishery worldwide (Kolding et al., 2014). Recently, however, this selectivity paradigm has become increasingly criticised for causing a range of adverse ecological effects (Garcia et al., 2012). Furthermore, the question of sustainability has evolved from a single species perspective (MSY) to an ecosystem per- spective (EAF), and the objectives are no longer just a matter of optimising certain outputs, but also of conserving the ecosystem as closely as possible in its original structure, composition and function in order to maintain its services. Clearly, the highly selective removal of particular constituents is incompatible with this additional objective of maintaining primary structure, and combining the two objectives becomes a challenge (Law et al., 2013). Under the present management paradigm, where the largest species and sizes in the system are selectively targeted, while the young and smallest species are protected, community structure will gradually change under exploitation. Fewer large fish means less predation on smaller sized-fish, which will result in an increased biomass of smaller sized-fish (Fig. 1). In combination these processes result in an increase in the slope of the community spectrum (Fig. 8). In the fishery this will be observed as the typical decrease in the mean size of the organisms caught, which is commonly used as a diagnostic indicator of intensive exploitation. The decrease in mean size, often interpreted as growth overfishing is thus an unavoidable consequence of selectively targeting large fish, which ironically - is designed to prevent the exact mechanism that it produces. The usual management responses, however, are calls for obeying or enforcing the minimum mesh, size and gear regulations, which will only exacerbate the symptoms that the interventions are meant to cure (Kolding and Zwieten, 2011). On the other hand, in unregulated systems fishers will invariably react in the opposite direction to the exasperation of managers. As the fishery expands and effort grows, the total annual production summed over all species has to be shared among an increasing number of fishers, which will result in a decrease in individual catch rate. The only means a fisher has to compensate for this is to i) invest in more gears - a limited option considering profit; ii) find new fishing grounds by investing in engine power - also a limited option as above; iii) change the large target species - if any left; or iv) start catching the more numerous and abundant smaller species and sizes in the system. The latter can only be achieved by decreasing the mesh sizes or by using less

Tab. 3. Catch and effort development in Lake Mweru. Demersal catches 5 year average centred on the year reported.

\begin{tabular}{|c|c|c|c|c|c|c|c|c|c|c|c|c|}
\hline \multirow[t]{2}{*}{ Year } & \multirow{2}{*}{$\begin{array}{c}\text { Effort } \\
\text { Fishers } \\
\text { Total }\end{array}$} & \multirow{2}{*}{$\begin{array}{l}\text { \% Gillnet } \\
\text { fishers }\end{array}$} & \multirow{2}{*}{$\begin{array}{c}\text { Gillnets } \\
\text { No. }\end{array}$} & \multirow{2}{*}{$\begin{array}{l}\% \text { Gillnets } \\
\text { of all gears }\end{array}$} & \multicolumn{4}{|c|}{ Mesh size $(\mathrm{mm})$} & \multirow{2}{*}{$\begin{array}{c}\text { No. } \\
\text { Chisense } \\
\text { dipnets }\end{array}$} & \multicolumn{2}{|c|}{ Catch (ton, Zambia) } & \multirow{2}{*}{$\begin{array}{c}\text { CPUE } \\
\text { (ton· year-1 } \\
\text { - } \text { fisher }^{-1} \text { ) }\end{array}$} \\
\hline & & & & & $<63$ & 63 & 76 & $>76$ & & $\begin{array}{l}\text { Gillnets } \\
\text { (5 yr avg) }\end{array}$ & Chisense & \\
\hline 1971 & 5963 & & & & & & + & +++ & & 8097 & & 1.4 \\
\hline 1986 & 7723 & & & & & & +++ & + & 450 & 8561 & 4500 & 1.7 \\
\hline 1992 & 9301 & $71 \%$ & 45057 & $95 \%$ & $9 \%$ & $49 \%$ & $22 \%$ & $20 \%$ & 1426 & 7051 & 30,000 & 4.0 \\
\hline 1997 & 12047 & $55 \%$ & 93,256 & $96 \%$ & $10 \%$ & $40 \%$ & $24 \%$ & $26 \%$ & 1729 & 8473 & 36,250 & 3.7 \\
\hline 2008 & 21222 & $62 \%$ & 435,848 & $99 \%$ & $6 \%$ & $44 \%$ & $29 \%$ & $21 \%$ & 1960 & 9197 & 50,000 & 2.9 \\
\hline
\end{tabular}

Bold and italics: chisense catches estimated from catch rates in Zwieten et al., 1996, 2003 and Mölsä, 2010; CPUE, catch per unit of effort. 
selective gears (Jul-Larsen et al., 2003). Typically this will result in entering into the realm of illegal fishing methods, and thus oppose the prescription of the managers. This typical development towards higher diversity and smaller specimen in the catch with increased pressure has been described as the fishing down process, and is widely believed to eventually result in resource degradation (Pauly et al., 1998). Welcomme (1999) describes the fishing down process in tropical freshwater fisheries, but also indicates that this is inevitable in a multispecies/gear fishery. If maximising yields while conserving fish assemblages is the goal, he argues, then the management challenge is to determine the acceptable total fishing pressure on the whole fish community and how to allocate this between different gears. This will be extremely difficult, he ac- knowledges, implying rigid enforcement of both mesh sizes and access. It also requires banning of gears and other fishing practices that impact species of smaller sizes, ... (Welcomme, 1999). As we have shown this may be the wrong approach from both ecological and social perspectives. Balanced harvesting actually requires fishing down replacing reduced predation mortality with fishing mortality on species and specimen of smaller sizes to maintain the community structure! In many known cases, community yields are maintained over a large range of fishing pressure (Lorenzen et al., 2006), which to a large extent can be explained by the fishing down process. In the low capital investment fisheries of African freshwaters effort seems largely self-regulated by the catch rates, which again are controlled by the productivity (Kolding
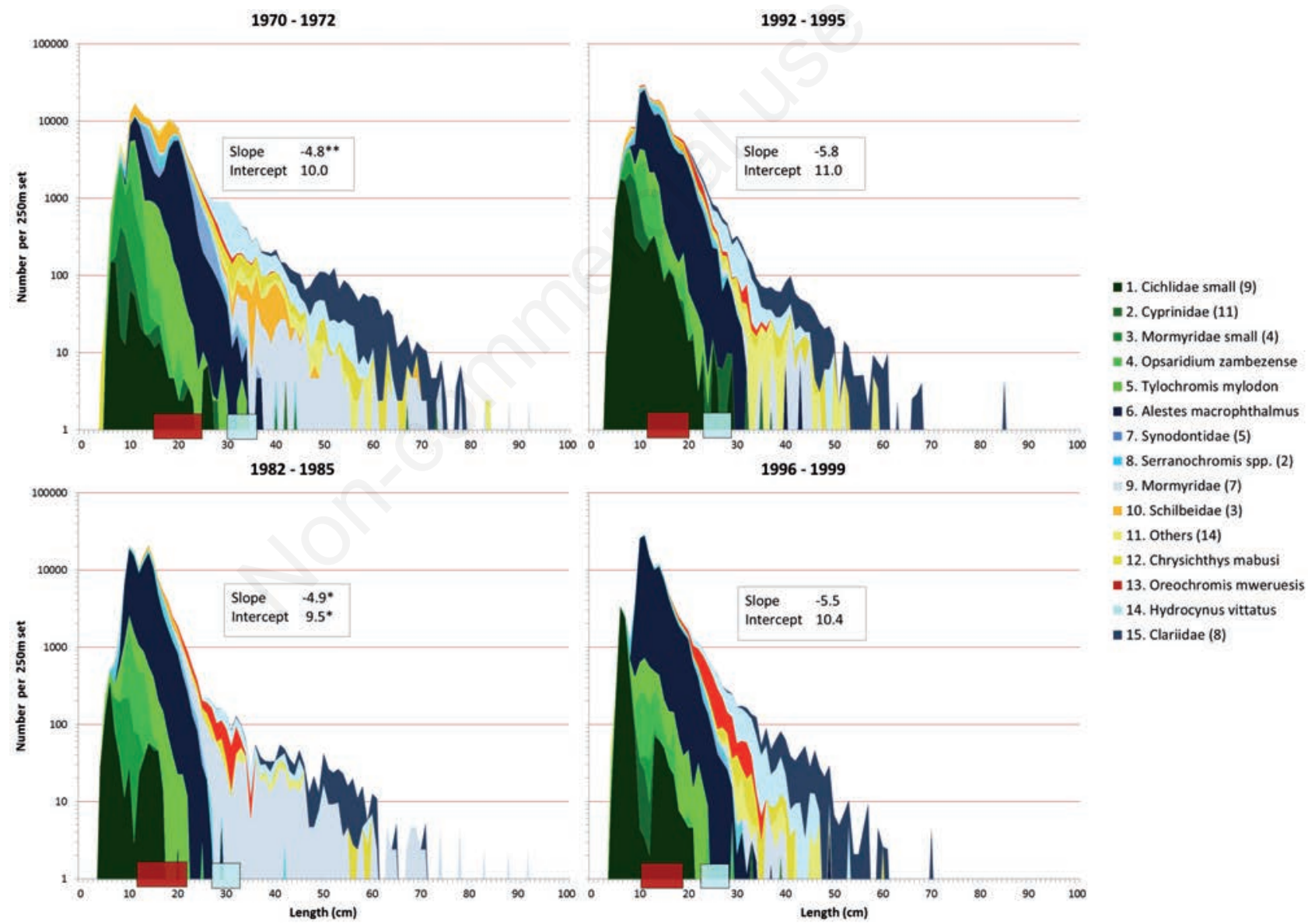

Fig. 6. $\log _{10}$ transformed standardized catch rates (an index of relative abundance) against the length of 15 species categories (numbered colours: species category with numbers in brackets) of the Lake Mweru fish community (fleet of experimental gillnets; 4 periods from 1970 - 1998). Coloured bars: size selectivity of the dominant mesh sizes used in the fishery for main target species with red (dark), Oreochromis mweruensis, Serranochromis spp. and Tylochromis mylodon; and blue (light), Hydrocynus vittatus. Over time the dominant mesh sizes used in the fishery decreased from $102 \mathrm{~mm}$ to $63 \mathrm{~mm}$. Slopes and intercepts of the abundance-size distributions obtained by an ANCOVA with period as co-variate. Significance levels of slopes and intercepts are against the final period 1996-1999 with $* \mathrm{P}<0.05$, ** $\mathrm{P}<0.01$. Adapted from Zwieten et al. (2003). 
and Zwieten, 2012). Lorenzen et al. (2006) did not observe this self-regulating relationship between CPUE and fishing effort. However, they did propose that high sustainable total yields under high effort levels was a result from shifting to the more productive smaller part of the fish community. The problem remaining for the how much question is to determine at what levels of fishing pressure the community structure actually begins to deteriorate. Nevertheless, the reviews of Jul-Larsen et al. (2003), Lorenzen et al. (2006) and Kolding and van Zwieten (2011; 2012), in a range of multispecies inland fisheries, indicate that classical symptoms of overfishing, i.e. when total population yield starts declining as a function of effort, is a relatively rare event, and that high sustainable community yields under increased effort are maintained by the fishing down process, which eventually will approximate balanced harvesting.

So, how do we asses these fisheries, and which metrics do we use? The fishing down process can be quantified by the mean trophic index (MTI) in the catches and the so-called Fishery in Balance (FiB) index (Pauly et al., 2000). While a decrease in MTI is considered a negative development, from the above examples and theory, we think that a decrease in the mean trophic level combined
A

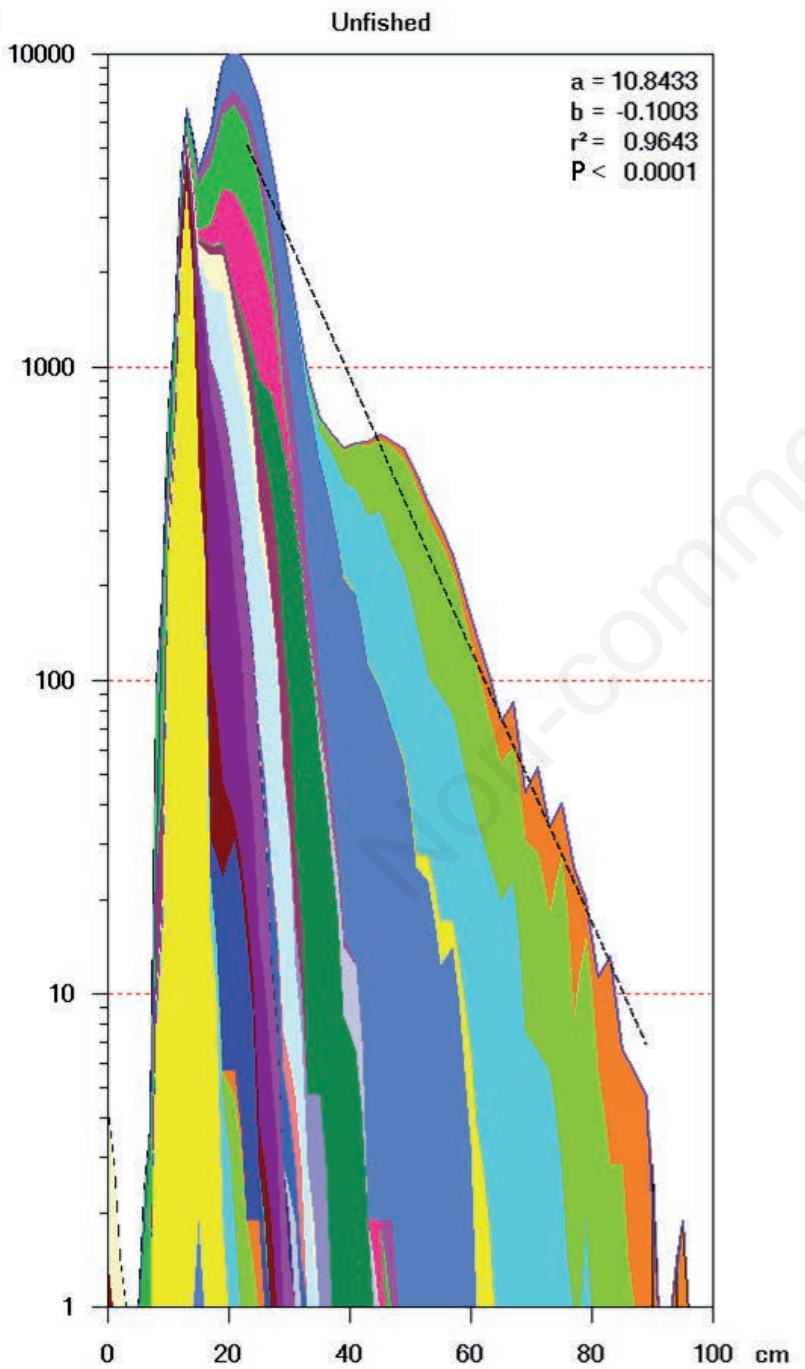

B

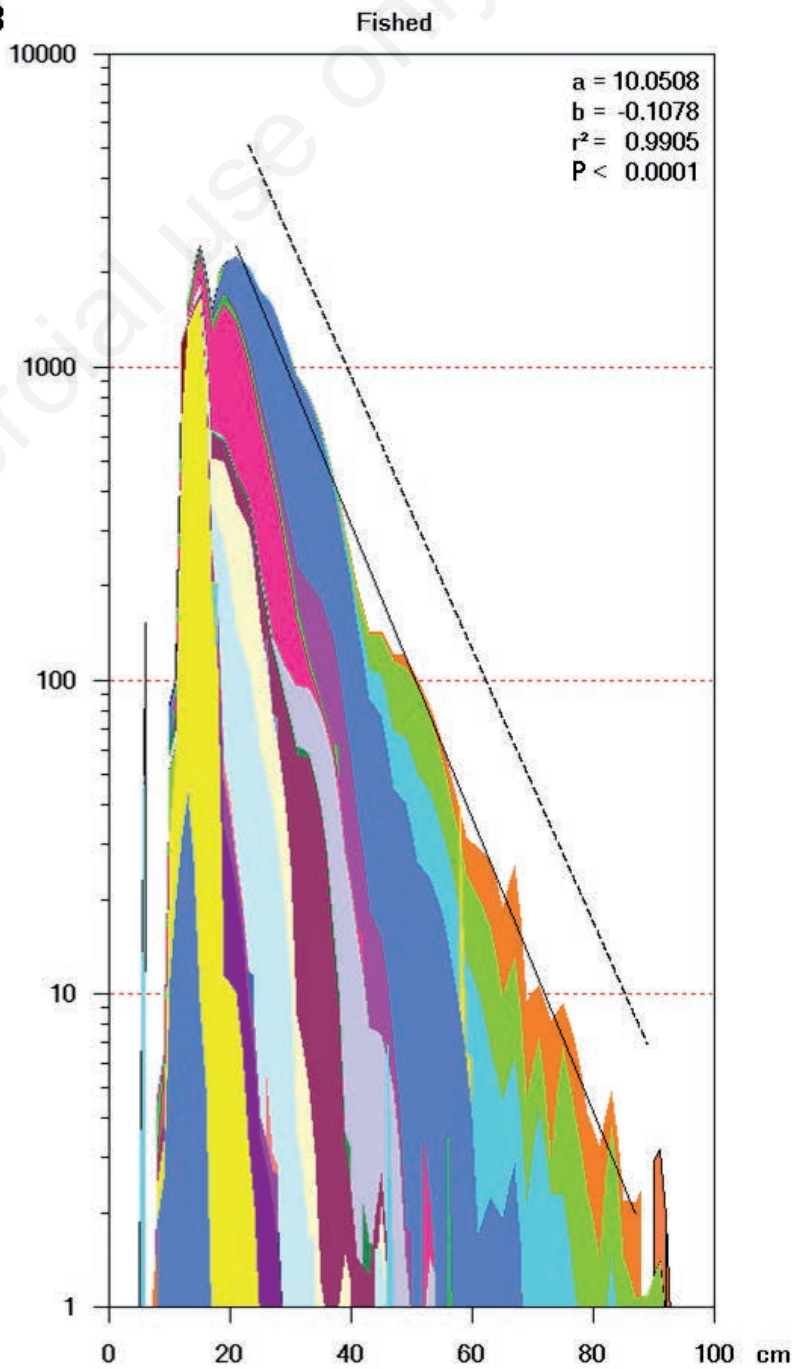

Fig. 7. Standardized biomass-size distributions in Lake Kariba from experimental fishing surveys. A) Unfished area, Zimbabwe. B) Heavily fished Zambian fishing grounds. Each colour (shade) represents a different species. No significant difference between the slopes (regression lines) of the unfished (dashed) and the fished (full) community indicates a significantly lower standing biomass but equal relative species and size compositions in the fished area. Modified from Kolding et al. (2003a). 
with a stable or increasing FiB index of the catches should actually be interpreted as a positive sign, and could just as well be indicating a move towards a more balanced harvest (sensu Garcia et al., 2012). Other indicators based on size, community structure, and abundance (CPUE) (Trenkel and Rochet, 2003; Shin et al., 2005; Charnov et al., 2013) can be used to evaluate community resilience to fishing and disturbance of primary structure (Fig. 8). Measures of community resilience to fishing for instance can be devised from combinations of indicators related to size, size distributions, $\mathrm{P} / \mathrm{B}$ ratios (equivalent to total mortality or intrinsic rate of natural increase under steady state) and $\mathrm{C} / \mathrm{P}$ ratios (equivalent to $\mathrm{F} / \mathrm{Z}$ or exploitation fraction) over size classes and trophic level of the catch
(Trophic Signature) of gears. Other pressure indicators could be found in the proportion of gears targeting specific size ranges. Measures of disruption of a community relate to species diversity, ratios of predator to prey, length by categories of $r$ - or K-selected species; maximum length in the community/by species; slope of the biomass-size distribution as a measure of total community turnover rate ( $\mathrm{P} / \mathrm{B}$ or total mortality), and internal structure of the sizespectrum as a measure of cascading effects. A recruitment index showing the annual production of recruitment by species will give indications of the prospective productivity of the community. Such an index is expected to be strongly related to environmental changes in system productivity, such as nutrient inputs indicated by fluctuating

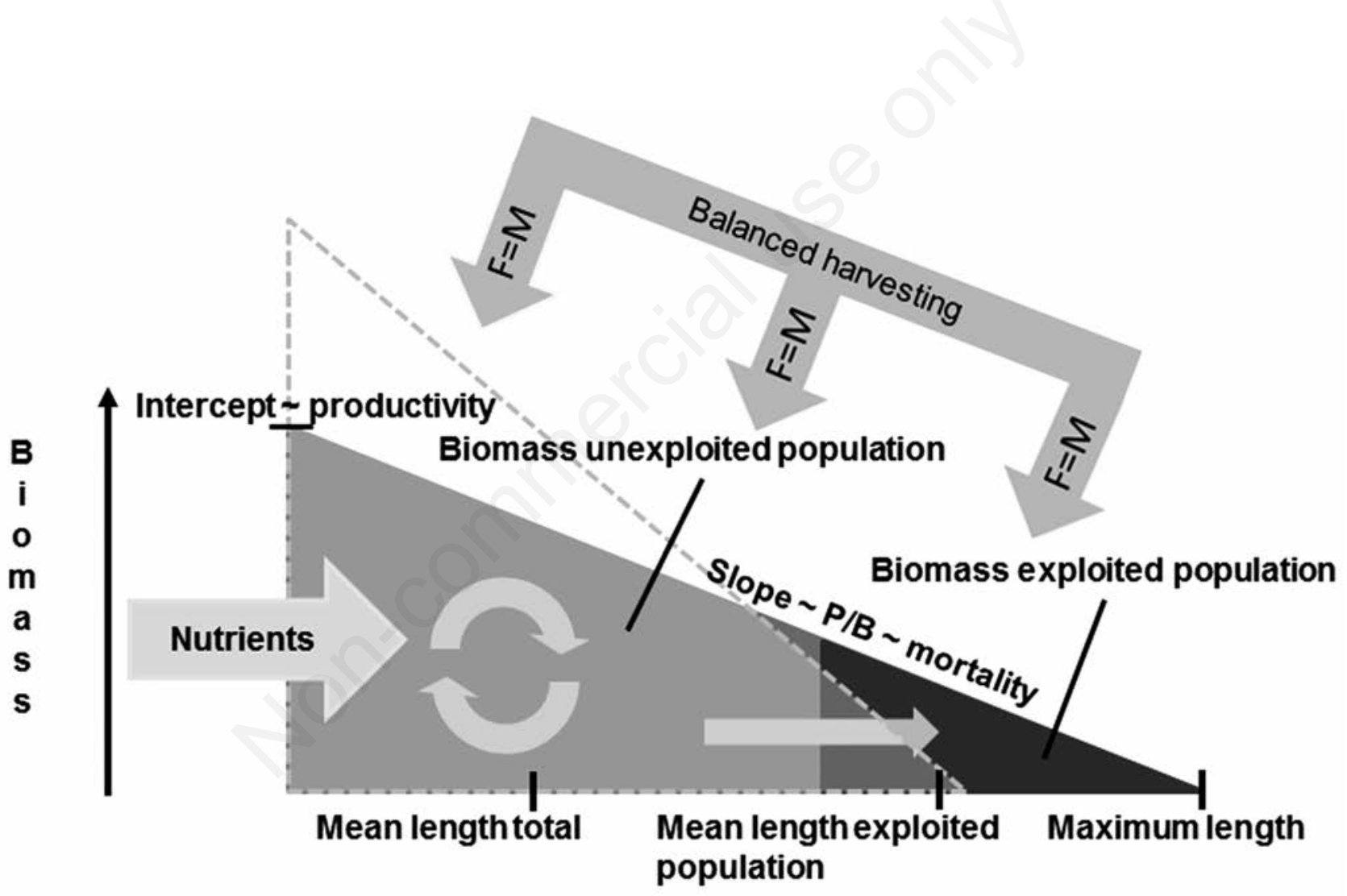

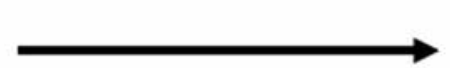

Size of fish
Fishing pressure

Fig. 8. A framework to analyse changes in a fish community depicted as a biomass size distribution with decreasing log-transformed biomass (or numbers) over size and affected by external (nutrients, selective fishing pressure and balanced harvesting) and internal (competition and predation) drivers (grey arrows). System stability is related to the steepness of the slope of the distributions: dotted triangle=unstable $r$-selected system, with high productivity and turnover rates; stable K-selected systems have lower slopes and P/B ratios. To evaluate community changes a range of size, catch per unit of effort (CPUE $\approx$ relative biomass) based indicators, and the slope and intercept with their interpretations are indicated. Under balanced harvesting the fishing mortality $(\mathrm{F})$ is approximately proportional to the natural mortality $(\mathrm{M})$ over the whole size range, leaving the slope unchanged, but the intercept lower. 
water levels. Lastly RLLF can position a particular system on a stability/productivity scale. However, the sensitivity to fishing, specificity and responsiveness of these indicators to fishing pressure on a community level is little investigated and needs further research.

In general, the stability of an ecosystem will be the major determinant of the size range of the fish community, the distribution of biomass over that size range as well as the sustainability, measured as the resilience to additional disturbances from fishing (Barnes et al., 2010; Plank and Law, 2012). The stability of a freshwater ecosystem was expressed by Jul-Larsen et al. (2003) through the RLLF in order to classify rivers, lakes and reservoirs in a continuum from highly stable to highly fluctuating environments, but RLLF is also significantly correlated with the productivity of a system (Kolding and Zwieten, 2012) and productivity is strongly correlated with the slope of the biomass-size spectrum (Jul-Larsen et al., 2003; Kolding and Zwieten, 2006). The RLLF index can therefore be used as a predictive indicator for classifying lakes and reservoirs from stable to pulsed systems, and thereby their potential productivity and resilience to external disturbances (Kolding and Zwieten, 2012). Floodplains, shallow lakes and man-made reservoirs in general have the highest water fluctuations, but also the highest fish yield per unit area, and even extreme fluctuations (amplitude higher than mean depth) seem only to accelerate biological processes. Water level fluctuations and RLLF are therefore strong potential sustainability indicators for fisheries.

In conclusion, sustainable fishing is a result of how we fish and how much we fish. On the how question, there is increasing empirical and theoretical evidence that balanced harvest (Garcia et al., 2012), will return the highest yields with the smallest demographic disturbances to the community. As such a fishing pattern will be predominantly targeting the smallest and most productive components (Law et al., 2012, 2013) In leaving a high proportion of the largest, but least productive, mature fish to survive and reproduce, balanced harvesting can in theory accommodate both a commercial or subsistence food fishery, and a recreational catch-and-release sports fishery in the same ecosystem, and thus ameliorate the traditional antagonism between the two groups of fishers. However, if there is a high consumer demand for large sized species, then this will require maximum size limitations in contrast to the conventional minimum size regulations (Gwinn et al., 2013). Nonetheless, a high demand for a broad range of species, including small fish that is easily dried and transported over large distances, exists in many tropical inland and coastal fisheries, indicating that in those situations yield is more important than commercial value of specific species and size classes (Lorenzen et al., 2006). On the how much question or the potential for production, the resilience versus vulnerability to exploitation can be evaluated through a simple physical disturbance indicator such as the RLLF. In open access African freshwater fisheries, with low technological development, there is a significant correlation between fishing effort, yield and RLLF (Kolding and Zwieten, 2012), which indicates that effort to a large extent is regulated by the productivity in such fisheries.

Sustainability in natural resources management has gradually evolved over the past decades from a purely output measure to a more holistic concept taking also the incidental impacts of fishing and the ability of the system to absorb these without changes into account. We hope that the framework of examples, new theory and ecological indicators presented here will contribute to this development and assist in better understanding of what is sustainable fishing.

\section{ACKNOWLEDGMENTS}

We sincerely thank the editors of this anniversary volume for their kind invitation to write this contribution, and we particularly appreciate their decision to publish it despite the intensity of some of the referee's comments, of whom twelve declined to review it.

\section{REFERENCES}

Andersen KH, Beyer JE, 2006. Asymptotic size determines species abundance in the marine size spectrum. Am. Nat. 168:54-61.

Andersen KH, Farnsworth KD, Pedersen M, Gislason H, Beyer JE, 2009. How community ecology links natural mortality, growth, and production of fish populations. ICES J. Mar. Sci. 66:1978-1984.

Anderson CNK, Hsieh C-h, Sandin SA, Hewitt R, Hollowed A, Beddington J, May RM, Sugihara G, 2008. Why fishing magnifies fluctuations in fish abundance. Nature 452:835-839.

Barnes C, Maxwell D, Reuman DC, Jennings S, 2010. Global patterns in predator-prey size relationships reveal size dependency of trophic transfer efficiency. Ecology 91:222-232.

Beverton RJH, Holt SJ, 1957. On the dynamics of exploited fish populations. Ministry of Agriculture: $553 \mathrm{pp}$.

Blanchard JL, Dulvy NK, Jennings S, Ellis JR, Pinnegar JK, Tidd A, Kell LT, 2005. Do climate and fishing influence size-based indicators of Celtic Sea fish community structure? ICES J. Mar. Sci. 62:405-411.

Brelsford WV, 1946. Fishermen of the Bangweulu swamps. The Rhodes-Livingstone Institute: $169 \mathrm{pp}$.

Bundy A, Fanning P, Zwanenburg KCT, 2005. Balancing exploitation and conservation of the eastern Scotian Shelf ecosystem: application of a 4D ecosystem exploitation index. ICES J. Mar. Sci. 62:503-510.

Chanda B, 1998. Effects of weir fishing on commercial fish stocks of the Bangweulu swamp fisheries, Luapula Province, Northern Zambia. MPhil Thesis, University of Bergen.

Charnov EL, Gislason H, Pope JG, 2013. Evolutionary assembly rules for fish life histories. Fish Fish. 14:213-224.

Conover DO, Munch SB, 2002. Sustaining fisheries yields over evolutionary time scales. Science 297:94-96. 
Daan N, Gislason H, Pope JG, Rice JC, 2005. Changes in the North Sea fish community: evidence of indirect effects of fishing? ICES J. Mar. Sci. 62:177-188.

Dankwa HR, Abban EK, Teugels GG. 1999. Freshwater fishes of Ghana: identification, distribution, ecological and economic importance. Musée Royale de L'Afrique Centrale: 53 pp.

Diamond B, Beukers-Stewart BD, 2011. Fisheries discards in the North Sea: waste of resources or a necessary evil? Rev. Fish. Sci. 19:231-245.

Froese R, 2004. Keep it simple: three indicators to deal with overfishing. Fish Fish. 5:86-91.

Garcia SM, Kolding J, Rice J, Rochet M-J, Zhou S, Arimoto T, Beyer JE, Borges L, Bundy A, Dunn D, Fulton EA, Hall M, Heino M, Law R, Makino M, Rijnsdorp AD, Simard F, Smith ADM, 2012. Reconsidering the consequences of selective fisheries. Science 335:1045-1047.

Garcia SM, Zerbi A, Aliaume C, Do Chi T, Lasserre G. 2003. The ecosystem approach to fisheries. Issues, terminology, principles, institutional foundations, implementation and outlook. FAO Fisheries Technical Paper. FAO.

Gordon DM, 2000. The making of a hinterland. Environment and politics in Mweru-Luapula from the 1880s to the 1990s. $\mathrm{PhD}$ Thesis, Princeton University.

Gordon DM, 2006. Nachituti's gift. Economy, society and environment in Central Africa. University of Wisconson Press: 304 pp.

Guénette S, Gascuel D, 2012. Shifting baselines in European fisheries: the case of the Celtic Sea and Bay of Biscay. Ocean Coast. Manage. 70:10-21.

Gwinn DC, Allen MS, Johnston FD, Brown P, Todd CR, Arlinghaus R, 2013. Rethinking length-based fisheries regulations: the value of protecting old and large fish with harvest slots. Fish Fish. DOI: 10.1111/faf.12053

Hsieh C-h, Yamauchi A, Nakazawa T, Wang WF, 2010. Fishing effects on age and spatial structures undermine population stability of fishes. Aquat. Sci. 72:165-178.

Huchzermeyer CF, 2013. Fish and fisheries of Bangweulu wetlands, Zambia. MSc thesis. Rhodes University, South Africa.

Jennings S, Pinnegar JK, Polunin NVC, Boon TW, 2001. Weak cross-species relationships between body size and trophic level belie powerful size-based trophic structuring in fish communities. J. Anim. Ecol. 70:934-944.

Jørgensen C, Enberg K, Dunlop ES, Arlinghaus R, Boukal DS, Brander K, Ernande B, Gårdmark AG, Johnston F, Matsumura S, Pardoe H, Raab K, Silva A, Vainikka A, Dieckmann U, Heino M, Rijnsdorp AD, 2007. Ecology: managing evolving fish stocks. Science 318:1247-1248.

Jul-Larsen E, Kolding J, Overå R, Raakjær Nielsen J, Zwieten PAMv, 2003. Management, co-management or no-management? Major dilemmas in the sustainable utilisation of SADC freshwater fisheries. Part 1: synthesis. FAO Fisheries Technical Paper No. 426/1. FAO, Rome.

Kapasa CK, 1998. Selective fishing of Alestes macrophthalmus (Alestiidae) using gillnets of small mesh sizes at fish aggregating devices (FADs) in the Mweru-Luapula fishery, Northern Zambia. PhD Thesis, University of Bergen.

Karenge LP, Kolding J, 1995. On the relationship between hydrology and fisheries in Lake Kariba, Central Africa. Fish. Res. 22:205-226.

Kelleher K. 2005. Discards in the world's marine fisheries. An update FAO Fisheries Technical Paper N. 470. FAO, Rome.

Kerr SR, Dickie LM. 2001. The biomass spectrum. A predatorprey theory of aquatic production. Columbia University Press: 320 pp.

Kolding, J. 1993. Population dynamics and life history styles of Nile tilapia (Oreochromis niloticus) in Fergusons Gulf, Lake Turkana, Kenya. Env. Biol. Fish. 37:25-46.

Kolding J, 1994. Plus ça change, plus c'est la même chose. On the ecology and exploitation of fish in fluctuating tropical environments. Dr. Scient. Thesis, University of Bergen.

Kolding J, Béné C, Bavinck M, 2014. Small-scale fisheries - importance, vulnerability, and deficient knowledge, In: S. Garcia, J. Rice and A. Charles (eds.), Governance for marine fisheries and biodiversity conservation. Interaction and Coevolution. Wiley-Blackwell (in press).

Kolding J, Musando B, Songore N, 2003a. Inshore fisheries and fish population changes in Lake Kariba, p. 67-99. In: E. JulLarsen, J. Kolding, R. Overå, J. Raakjær Nielsen and P.A.M.v. Zwieten (eds.), Management, Co-management or No-management? Major dilemmas in southern African freshwater fisheries. FAO Fisheries Technical Paper 426/2. FAO.

Kolding J, Ticheler H, Chanda B, 2003b. The Bangweulu swamps - A balanced small-scale multispecies fishery, p. 34-66. In: E. Jul-Larsen, J. Kolding, R. Overå, J. Raakjær Nielsen and P.A.M.v. Zwieten (eds.), Management, Co-management or No-management? Major dilemmas in southern African freshwater fisheries. FAO Fisheries Technical Paper 426/2. FAO.

Kolding J, Zwieten PAMv, 2006. Improving productivity in tropical lakes and reservoirs. WorldFish Center: $139 \mathrm{pp}$

Kolding J, Zwieten PAMv, 2011. The tragedy of our legacy: how do global management discourses affect small-scale fisheries in the South? Forum for Development Studies 38:235-265.

Kolding J, Zwieten PAMv, 2012. Relative lake level fluctuations and their influence on productivity and resilience in tropical lakes and reservoirs. Fish. Res. 115-116:99-109.

Law R, 2000. Fishing, selection and phenotypic evolution. ICES J. Mar. Sci. 57:659-668.

Law R, Kolding J, Plank MJ, 2013. Squaring the circle: reconciling fishing and conservation of aquatic ecosystems. Fish Fish. DOI: 10.1111/faf.12056

Law R, Plank MJ, Kolding J, 2012. On balanced exploitation of marine ecosystems: results from dynamic size spectra. ICES J. Mar. Sci. 69:602-614.

Lorenzen K, Almeida O, Arthur R, Garaway C, Khoa SN, 2006. Aggregated yield and fishing effort in multispecies fisheries: an empirical analysis. Can. J. Fish. Aquat. Sci. 63:1334-1343.

Malasha I. 2003. Colonial and post colonial fisheries regulations: the cases of Zambia and Zimbabwe, p. 253-266. In: E. Jul-Larsen, J. Kolding, J.R. Nielsen, R. Overa and P.A.M.v. Zwieten (eds.), Management, co-management or no management? Major dilemmas in southern African freshwater fisheries. Part 2: case studies. FAO Fisheries Technical Paper N. 426/2. FAO, Rome.

Misund OA, Kolding J, Fréon P, 2002. Fish capture devices in industrial and artisanal fisheries and their influence on management, p. 13-36. In: P.J.B. Hart and J.D. Reynolds (eds.), Handbook of Fish Biology and Fisheries, 2. Blackwell Science.

Mölsä H, 2010. Fisheries management plan for Mweru-Luapula, Zambia. PLARD, Programme for Luapula agricultural 
and rural development. Fish Innovation Centre Ltd., Finland: $51 \mathrm{pp}$.

Pauly D, Christensen V, Dalsgaard J, Froese R, Torres F Jr, 1998. Fishing down marine food webs. Science 279:860-863.

Pauly D, Christensen V, Walters C, 2000. Ecopath, ecosim, and ecospace as tools for evaluating ecosystem impact of fisheries. ICES J. Mar. Sci. 57:697-706.

Pianka ER, 1970. On $\mathrm{r}$ and K selection. Am. Nat. 104:592-597.

Pikitch E, Boersma PD, Boyd IL, Conover DO, Cury P, Essington T, Heppell SS, Houde ED, Mangel M, Pauly D, Plagányi É, Sainsbury K, Steneck RS, 2012. Little fish, big impact: managing a crucial link in ocean food webs. Lenfest Ocean Program, Washington: $108 \mathrm{pp}$. Available at http://www. lenfestocean.org/foragefishreport

Plank M, Law R, 2012. Ecological drivers of stability and instability in marine ecosystems. Theor. Ecol. 5:465-480.

Rice J, Gislason H, 1996. Patterns of change in the size spectra of numbers and diversity of the North Sea fish assemblage, as reflected in surveys and models. ICES J. Mar. Sci. 53:1214-1225.

Ryder RA, Kerr SR, Loftus KM, Regier HA, 1974. The morphoedaphic index, a fish yield estimator - review and evaluation. J. Fish. Res. Board Can. 31:663-688.

Sharpe DMT, Hendry AP, 2009. Life history change in commercially exploited fish stocks: an analysis of trends across studies. Evol. Appl. 2:260-275.

Sheldon RW, Prakash A, Sutcliffe WH Jr, 1972. The size distribution of particles in the ocean. Limnol. Oceanogr. 17:327-340.

Shin YJ, Rochet MJ, Jennings S, Field JG, Gislason H, 2005. Using size-based indicators to evaluate the ecosystem effects of fishing. ICES J. Mar. Sci. 62:384-396.

Trenkel VM, Rochet MJ, 2003. Performance of indicators derived from abundance estimates for detecting the impact of fishing on a fish community. Can. J. Fish. Aquat. Sci. 60:67-85. van Wijk SJ, Taylor MI, Creer S, Dreyer C, Rodrigues FM, Ramnarine IW, van Oosterhout C, Carvalho GR, 2013. Experimental harvesting of fish populations drives genetically based shifts in body size and maturation. Front. Ecol. Environ. 11:181-187.

Welcomme RL, 1999. A review of a model for qualitative evaluation of exploitation levels in multi-species fisheries. Fish. Manage. Ecol. 6:1-19.

Winemiller K, Rose K, 1992. Patterns of life-history diversification in North American fishes: Implications for population regulation. Can. J. Fish. Aquat. Sci. 49:2196-2218.

Zhou S, Smith ADM, Punt AE, Richardson AJ, Gibbs M, Fulton EA, Pascoe S, Bulman C, Bayliss P, Sainsbury K, 2010. Ecosystem-based fisheries management requires a change to the selective fishing philosophy. P. Natl. Acad. Sci. USA 107:9485-9489.

Zwieten PAMv, Aarnink BHM, Kapasa CK, Ngalande P, 1996. The biology, fishery and trade of chisense from Mweru-Luapula. Dept. of Fisheries, Nchelenge, Zambia: 115 pp.

Zwieten PAMv, Béné C, Kolding J, Brummett R, Valbo-Jørgensen J, 2011. Review of tropical reservoirs and their fisheries in developing countries: the cases of Lake Nasser, Lake Volta and Indo-Gangetic Basin reservoirs. FAO Fisheries Technical Paper N. 557. FAO, Rome.

Zwieten PAMv, Goudswaard PC, Kapasa CK, 2003. Mweru-Luapula is an open exit fishery where a highly dynamic population of fishers makes use of a resilient resource base, $p$. 1-33. In: E. Jul-Larsen, J. Kolding, R. Overå, J. Raakjær Nielsen and P.A.M.v. Zwieten (eds.), Management, co-management or no-management? Major dilemmas in southern African freshwater fisheries. FAO Fisheries Technical Paper N. 426/2. FAO, Rome. 